\title{
Effect of vitamin A supplementation on diarrhoea and acute lower-respiratory-tract infections in young children in Brazil
}

\author{
Mauricio L Barreto, Leonor M P Santos, Ana Marlucia O Assis, Maria Purificaçao N Araújo, Gilmor G Farenzena, \\ Paulo A B Santos, Rosimeire L Fiaccone
}

\section{Summary}

A beneficial effect of periodic vitamin A supplementation on childhood mortality has been demonstrated, but the effect on morbidity is less clear. We investigated the effect of vitamin A supplementation on diarrhoea and acute lower-respiratorytract infections (ALRI) in children from northeastern Brazil in a randomised, double-blind, placebo-controlled community trial.

1240 children aged 6-48 months were assigned vitamin A or placebo every 4 months for 1 year. They were followed up at home three times a week, and data about the occurrence and severity of diarrhoea and ALRI were collected. Any child with cough and respiratory rate above 40 breaths per min was visited by a paediatrician. The overall incidence of diarrhoea episodes was significantly lower in the vitamin-Asupplemented group than in the placebo group (18.42 vs $19.58 \times 10^{-3}$ child-days; rate ratio 0.94 [95\% Cl 0.90-0.9 8]). The benefit of supplementation was greater as regards severe episodes of diarrhoea; the incidence was $20 \%$ lower in the vitamin A group than in the placebo group (rate ratio 0.80 $[0.65-0.98])$. With the standard definition of diarrhoea $(\geqslant 3$ liquid or semi-liquid stools in $24 \mathrm{~h}$ ) the effect of vitamin $\mathrm{A}$ on mean daily prevalence did not reach significance, but as the definition of diarrhoea was made more stringent (increasing number of stools per day), a significant benefit became apparent, reaching for diarrhoea with 6 or more liquid or semi-liquid stools in $24 \mathrm{~h}$ a $23 \%$ lower prevalence. We found no effect of vitamin A supplementation on the incidence of ALRI.

The reduction in severity of diarrhoea may be the most important factor in the lowering of mortality by vitamin A supplementation.

Lancet 1994; 344: 228-31

\section{Introduction}

Several studies have tried to find out whether vitamin A supplementation in young children can reduce mortality or morbidity. Six placebo-controlled, community-based trials found significant reductions in mortality ranging from $19 \%$ to $54 \%,^{1-6}$ but two others ${ }^{7,8}$ found no effect on mortality. Three meta-analyses of these trials have shown average reductions in all-cause mortality of $23 \%{ }^{9}$ and $30 \%{ }^{10,11}$ with vitamin A supplementation of children aged 6 months to 6 years.

The picture is less clear as regards the expected decrease in morbidity, the presumed underlying cause of the observed fall in mortality. 9 Among completed communitybased trials, two with satisfactory methods reported no significant difference in the prevalence or duration of diarrhoea or of acute lower-respiratory-tract infections (ALRI) between vitamin A and placebo groups. ${ }^{6,12,13}$ The Ghana study ${ }^{12}$ found evidence that, although the occurrence of disease was not affected, its severity was reduced. Another trial, in Indonesia, showed a slight negative effect of vitamin A supplementation on ALRI, but has so far been reported only in abstract form. ${ }^{14}$ The only previous trial in Latin America or the Caribbean showed slight, but significant, increases in the prevalence of cough and rapid breathing and of diarrhoea in the vitamin-Asupplemented group. ${ }^{15}$

Vitamin A deficiency and xerophthalmia occur in some parts of northeastern Brazil. ${ }^{16,17}$ Our study on the effects of periodic vitamin A supplementation on diarrhoea and ALRI was carried out in an area where vitamin A deficiency occurs biochemically, but seldom reaches the clinical stages. We aimed primarily to assess the effects of large doses of vitamin A on diarrhoea incidence, prevalence, and severity, but AL.RI were also included as a major outcome.

\section{Patlents and methods}

Study design and sample

A masked, placebo-controlled community trial was conducted in northeastern Brazil in a cohort of 1240 children ( 620 placebo, 620 vitamin A supplemented) aged 6-48 months at baseline and followed up from December, 1990, to December, 1991. This sample size was estimated to give a power of $90 \%(\alpha=5 \%)$ to detect a $15 \%$ reduction in the incidence of diarrhoea.

The study was located in Serrinha, $170 \mathrm{~km}$ northwest of Salvador, capital of the state of Bahia. It is a town of about 30000 inhabitants, situated in a semi-arid zone, with a hot, dry climate and irregular rainfall. Public health services are inadequate. In a survey of vitamin A status in the area of Serrinha and six neighbouring towns, we measured serum retinol concentrations in a sample of 563 preschool children. No signs or symptoms of xerophthalmia were recorded, but in the whole region, $15.5 \%$ of children had biochemical deficiency (serum concentration $<0.35$ $\mu \mathrm{mol} / \mathrm{L})$ and for the subgroup from Serrinha $(\mathrm{n}=90) 7 \cdot 4 \%$ had biochemical deficiency. These rates satisfy WHO criteria for vitamin A deficiency to be considered a public health problem. ${ }^{18}$ 


\begin{tabular}{|c|c|c|}
\hline & $\begin{array}{l}\text { Vitamin } A \\
(n=620)\end{array}$ & $\begin{array}{l}\text { Placebo } \\
(n=620)\end{array}$ \\
\hline \multicolumn{3}{|l|}{ Demographic features } \\
\hline Mean (SD) age (days) & $840(379)$ & $859(370)$ \\
\hline$\% \mathrm{M} / \mathrm{F}$ & $533 / 467$ & $512 / 488$ \\
\hline Hospital births (\%) & 805 & 773 \\
\hline \multicolumn{3}{|l|}{ Nutrittion } \\
\hline \% currently breastfed & & 138 \\
\hline Median (IQR) duration breastfeeding (mo) & $40(100)$ & $40(10.0)$ \\
\hline Median (IQR) duration exclusive breastfeeding (mo) & $10(20)$ & $10(20)$ \\
\hline \multicolumn{3}{|l|}{ Vaccination (\%) } \\
\hline Bacille Calmette Guerin & 840 & 862 \\
\hline Oral poliovaccine & 659 & 668 \\
\hline Diphtherla, tetanus, pertussis & 480 & 520 \\
\hline Measles & 649 & 652 \\
\hline \multicolumn{3}{|l|}{ Anthropometric status (\%) } \\
\hline Height for age $<-2 Z$ score & $23 \cdot 6$ & 201 \\
\hline Weight for age $<-2 Z$ score & 121 & 131 \\
\hline Weight for height $<-2 Z$ score & 14 & 14 \\
\hline \multicolumn{3}{|l|}{ Cllnkcal history (\%) } \\
\hline Measles & 99 & 112 \\
\hline Pneumonia & 46 & 41 \\
\hline Asthma & 146 & 136 \\
\hline Any illness in past 2 wk & 222 & 229 \\
\hline Dlarrhoea in past 2 wk & 146 & 138 \\
\hline \multicolumn{3}{|l|}{ Soclooconomic status (\%) } \\
\hline Piped water in home & 961 & $96 \cdot 4$ \\
\hline Electricity & 936 & 964 \\
\hline Refrigerator & 395 & 377 \\
\hline Television & 591 & 572 \\
\hline Father completed primary education & 723 & 710 \\
\hline Mother completed primary education & 768 & 761 \\
\hline
\end{tabular}

Table 1: Demographic, clinical, nutritional, and socloeconomic characteristics at baseline

At the beginning of the trial, children were identified by a census of the poorest neighbourhoods of Serrinha. Eligible children had proof of age between 6 and 48 months and the parents consented for them to take part. Reasons for exclusion included active xerophthalmia, measles within the previous 30 days, high-dose vitamin A supplementation in the previous 6 months (100000 IU or more), and weight-for-age less than $60 \%$ of the National Center for Health Statistics standard population median. ${ }^{19}$

The study was approved by the National Institute of Nutrition, Ministry of Health, Brazil, and by the ethics committee of the School of Medicine, Federal University of Bahia. After meetings with community leaders and the families involved in all the neighbourhoods studied, an informed consent form was signed or fingerprinted by the parent or guardian of each participant. Local doctors were informed and shown the identity card issued to all children stating that they were taking part in a trial and might be receiving large doses of retinol palmitate.

\section{Randomisation and dosing}

Children were randomly assigned to receive vitamin A or placebo four times-at the start of the trial and every 4 months thereafter. The dose was $100000 \mathrm{IU}$ for children younger than 12 months and 200000 IU for older participants. All supplements were given by the three senior investigators, who kept records of delivery. The study was kept double-blind and only an external investigator had the codes for the individually wrapped and numbered capsules. The gelatinous capsules of vitamin A and placebo (supplied by Hoffman La Roche) were identical in appearance and were unwrapped just before administration.

\section{Follow-up}

Morbidity data were collected at household visits by local field workers; each worker was responsible for about 60 children ( 30 visits daily). Children were visited three times per week (Monday, Wednesday, Friday, or Tuesday, Thursday, Saturday), corresponding to a recall period of 48-72 h. Data on the occurrence of diarrhoea and respiratory infections were collected. Whenever diarrhoea was reported, a complete investigation of signs and symptoms of diarrhoea was undertaken, including questions on the

\begin{tabular}{|c|c|c|c|c|}
\hline $\begin{array}{l}\text { No of llquld } \\
\text { stools/day }\end{array}$ & Vitamin A & Placebo & $\begin{array}{l}\text { Ratlo } \\
\text { vitamin A/ } \\
\text { placebo }\end{array}$ & $\mathbf{p}$ \\
\hline$\geqslant 3$ & 00478 & 00517 & $\overline{092}$ & 0074 \\
\hline$\geqslant 4$ & 00232 & 00259 & 090 & 0049 \\
\hline$\geqslant 5$ & 00099 & 00123 & 080 & 0005 \\
\hline$\geqslant 6$ & 00043 & 00056 & 077 & 0006 \\
\hline aretaker's definitlos & 00588 & 00658 & 089 & 0012 \\
\hline
\end{tabular}

Table 2: Mean dally prevalence of dlarrhoea according to different definitions

presence of vomiting, mucus or blood in the stools, fever, use of medicines, use of any rehydration therapy, medical care, and hospital admission. Whenever cough was reported, the child's respiratory rate was measured twice. If the average value was 40 breaths per min or higher or if chest indrawing or nasal flaring was observed, the case was reported to the project's headquarters and the paediatrician visited the child as soon as possible. He requested chest radiography and referred the child to hospital if necessary. Whenever children in the study were admitted to local hospitals on the parents' initiative, the field worker immediately reported to headquarters and our paediatrician visited the child and collected information from the hospital records. Every 4 months, at the time of dosing, children were examined for ocular signs and symptoms of vitamin A deficiency and anthropometric measurements were made. Any child who did not receive the vitamin A/placebo dose on the scheduled date or after two home visits to deliver the supplement was taken to be lost to follow-up from that point onwards.

\section{Definitions}

To ensure uniformity of recall for all parents and guardians, the $24 \mathrm{~h}$ period was defined as the time from the moment the child woke up one day until he or she woke up the next day. A day with diarrhoea was defined as 3 or more liquid or semi-liquid motions reported in a $24 \mathrm{~h}$ period. ${ }^{20}$ However, since the number of motions per $24 \mathrm{~h}$ was recorded, we were able to define other thresholds used as proxies of diarrhoea severity. ${ }^{21}$ The parent or guardian's perception about whether or not the child had diarrhoea in each $24 \mathrm{~h}$ period was also recorded. An episode of diarrhoea was defined as a sequence of days with diarrhoea and the episode was considered finished when there were 3 or more days without diarrhoea. ${ }^{20}$ Mild diarrhoea was defined as an episode of 1-2 days' duration, moderate diarrhoea as an episode of 3 or more days' duration with a mean of 4 or fewer liquid or semi-liquid motions per $24 \mathrm{~h}$, and severe diarrhoea as an episode of 3 or more days' duration with a mean of 5 or more liquid or semi-liquid motions per $24 \mathrm{~h}$.

An episode of ALRI was defined as cough plus a respiratory rate of 50 breaths per min or higher for children under 12 months, and 40 breaths per min or higher for older children. An alternative definition ( 50 breaths per min or more for all children) was also investigated. A new episode was defined if there was an interval of 14 or more ALRI-free days. Pneumonia was diagnosed by the paediatrician based on clinical judgment and radiological findings.

\section{Data quality control, processing, and analysis}

Strict data quality control was maintained throughout the trial; it included a hierarchic scheme of area supervisors, trial supervisors, and the principal investigators. Each week, $10 \%$ of the studied children were randomly selected for re-interviews by the principal investigators. Data from paired interviews were immediately compared to verify the performance of the individual team members, and major problems were discussed by the trial team at fortnightly meetings. Each form was reviewed, first by a trained field worker and then by the area supervisor, before being handed in for data entry.

Data were entered onto microcomputers by two clerks at the project headquarters under a programme developed to simplify the process and to avoid errors. A $10 \%$ sample of the data entered by each clerk was re-entered by the other and checked for consistency. In addition, data were listed periodically for visual checks. 


\begin{tabular}{|c|c|c|c|c|c|}
\hline \multirow{2}{*}{$\begin{array}{l}\text { Eplsode } \\
\text { severity* }\end{array}$} & \multicolumn{2}{|c|}{ Vitamin A } & \multicolumn{2}{|c|}{ Placebo } & \multirow{2}{*}{$\begin{array}{l}\text { Rate ratio } \\
\text { (95\% Cl) }\end{array}$} \\
\hline & No & $\begin{array}{l}\text { Incidence } \\
\left(\times 10^{-3}\right. \\
\text { child-days })\end{array}$ & No & $\begin{array}{l}\text { Incidence } \\
\left(\times 10^{-3}\right. \\
\text { child-days })\end{array}$ & \\
\hline Mild & 2131 & 1048 & 2179 & $10 \cdot 80$ & $097(091-103)$ \\
\hline Moderate & 1614 & 794 & 1770 & 877 & $091(085-098)$ \\
\hline Severe & 165 & 081 & 204 & 101 & $080(065-098)$ \\
\hline Total & 3745 & 1842 & 3949 & 1958 & $094(090-098)$ \\
\hline
\end{tabular}

*Defined in methods section.

Table 3: Incidence of eplsodes of diarrhoea according to severity

The mean daily prevalence of diarrhoea and ALRI was estimated by calculating prevalence rates for each child and dosing round separately. In each treatment group, the results were averaged. The $95 \% \mathrm{CI}$ of the rate ratios of the incidence of diarrhoea and ALRI episodes were estimated by a Poisson regression model of the type $\mathrm{IR}=\exp (\mathrm{a}+\mathrm{b}$ [treatment]), where $\mathrm{IR}=$ number of episodes per child-days. Epi-info (version 5), SPSS-PC Plus (version 4), DEPID, and EGRET software were used for statistical analysis.

\section{Results}

Demographic, health, nutritional, and socioeconomic characteristics were similar in the two groups (table 1). The total loss in follow-up time was $10.3 \%$, equally distributed between the study groups. There were 203252 child-days of follow-up in the vitamin A group and 201656 in the placebo group. The main reason for loss to follow-up was migration away from the study area. No cases of xerophthalmia were found at baseline or during follow-up. There were 4 deaths, 2 in each treatment group.

9 children excluded from the trial because of severe weight deficits were given vitamin $A$, special nutrition education sessions with the team's nutritionists, and, for the most severely deprived families, food supplements obtained from government programmes. No child was excluded because of xerophthalmia, measles, or previous high-dose vitamin A supplements.

\section{Diarrhoea}

The mean daily prevalence of diarrhoea with various definitions is given in table 2 . As the definition of diarrhoea became more stringent, the vitamin $\mathrm{A} /$ placebo ratio showed a sustained decrease. The vitamin A group had mean daily prevalence rates $8 \%, 10 \%, 20 \%$, and $23 \%$ lower than those of the placebo group, with increasing stringency of diarrhoea definition. When the parent or guardian's definition of diarrhoea was used, the prevalence of diarrhoea was $11 \%$ lower in the vitamin A group than in the placebo group ( $\mathrm{p}=0.012)$.

The overall incidence of any episode of diarrhoea was $6 \%$ smaller in the vitamin A than in the placebo group (table 3). The overall incidence in the vitamin $A$ and placebo groups (18.42 and $19.58 \times 10^{-3}$ child-days) corresponds to 6.7 and $7 \cdot 1$ episodes per child per year, respectively. There was no significant difference between the groups in the incidence of mild episodes, but both moderate and severe episodes were less common in the vitamin A group (table 3 ).

Blood in the stools was reported in $6.7 \%$ and $7.0 \%$ of episodes in the vitamin A and placebo groups, respectively, (rate ratio 0.97 [95\% CI 0.82-1.14]) and mucus in the stools was reported in $35.2 \%$ and $33.2 \%(1.06$ [0.99-1.13]). Four or more episodes of vomiting occurred during $3.5 \%$ and $4 \cdot 1 \%$ of diarrhoeal episodes, respectively $(0 \cdot 84[0 \cdot 67-1 \cdot 05])$. Medical care was sought less frequently, though not significantly so, in the vitamin A group than in the placebo group ( 1.9 vs $2.5 \%$ of episodes; rate ratio $0.77[0.57-1.05]$ ).

\begin{tabular}{|c|c|c|c|c|c|}
\hline \multirow[t]{2}{*}{ Definltion } & \multicolumn{2}{|c|}{ Vltamin A } & \multicolumn{2}{|c|}{ Placebo } & \multirow{2}{*}{$\begin{array}{l}\text { Rate ratio } \\
\text { (95\% Cl) }\end{array}$} \\
\hline & No & $\begin{array}{l}\text { Incidence } \\
\left(\times 10^{-4}\right. \\
\text { child-days })\end{array}$ & No & $\begin{array}{l}\text { Incidence } \\
\left(\times 10^{-4}\right. \\
\text { child-days })\end{array}$ & \\
\hline ALRI-1 & 546 & 2686 & 556 & 2757 & $097(086-109)$ \\
\hline ALRI-2 & 147 & 723 & 143 & 709 & $102(081-128)$ \\
\hline Pneumonia* & 17 & 084 & 18 & 089 & 094 (0 48-1 82) \\
\hline
\end{tabular}

ALRI-1 $=$ respiratory rate $\geqslant 40 / \mathrm{min}$ to $12 \mathrm{mo}$, or $\geqslant 50 / \mathrm{min}$ for older children;

ALRI- $2=$ respiratory rate $\geqslant 50 / \mathrm{min}$ for any age.

*Diagnosed by the paediatrician, on basis of chest radiography and/or clinical judgment.

Table 4: Incidence of ALRI episodes according to different

definitions

\begin{tabular}{|c|c|c|c|c|}
\hline & Vitamin A & Placebo & Ratio* & p \\
\hline Cough & 02429 & 02388 & $\overline{099}$ & 057 \\
\hline Cough + fever & 00289 & 00282 & 099 & 090 \\
\hline Cough + IRR & 00124 & 00129 & 096 & 074 \\
\hline
\end{tabular}

IRR $=$ increased respiratory rate $(\geqslant 50 / \mathrm{min}$ for children $6-12$ months and $\geqslant 40 / \mathrm{min}$ for older children).

*Vitamin A/placebo.

Table 5: Mean daily prevalence of respiratory signs and symptoms

There was no difference between the treatment groups in the frequency of hospital admissions $(0.9 \%$ and $0.7 \% ; 1.24$ [0.75-2.05]). Measles was associated with $0 \cdot 1 \%$ (5 cases) and $0.2 \%$ (9 cases) of the diarrhoeal episodes in the vitamin $A$ and control groups, respectively.

\section{ALRI}

The number of cases diagnosed as pneumonia by the paediatrician was substantially lower than the frequency of ALRI reported by the field workers (table 4). Irrespective of the definition, there were no significant differences in incidence between the treatment groups. Similarly, analysis of respiratory signs and symptoms such as daily prevalence of cough (alone or associated with fever) or high respiratory rate showed no significant differences between the groups (table 5).

\section{Discussion}

Vitamin A supplementation had no detectable effect on the incidence, prevalence, or severity of ALRI in this population. Studies in Indonesia ${ }^{14}$ and Haiti ${ }^{15}$ detected higher frequencies of episodes of cough accompanied by raised respiratory rates in vitamin-A-supplemented children. These results could indicate potentially harmful effects of vitamin A supplementation. Stansfield et $a^{15}$ suggested that increased ability of the vitamin-Asupplemented child to respond to infection could have caused this finding, because the response would lead to more prominent signs and symptoms. Those two studies ${ }^{14,15}$ were conducted in areas with greater degrees of vitamin A deficiency than Serrinha.

Both the prevalence and incidence rates for diarrhoea in this study were lower than we expected from reports on other places in northeastern Brazil. A prospective study of urban slum children in a large city in the region ${ }^{22}$ found an incidence of 11.4 episodes per child-year of any type of diarrhoea; we found $6 \cdot 7$ and $7 \cdot 1$ episodes per child-year in the vitamin $A$ and placebo group. The most likely explanation for this discrepancy is socioeconomic differences between the communities. It is possible also that the frequent visits by our field workers increased families' awareness of the importance of disease prevention and enabled early detection and treatment of childhood diarrhoea. This factor could also explain the lack of 
significant differences in health service use between the groups. Children with severe weight-for-age deficits were excluded from this trial. We might have detected a greater effect of vitamin A supplementation if we had included all children.

By contrast with previous studies, ${ }^{6,12,13}$ our study was able to describe clearly the effect of vitamin A supplementation on the severity of diarrhoea. Previous morbidity trials collected data weekly, whereas in our study data were collected three times a week, so the morbidity recall period was shorter and precision and detail of the data collected (such as motions per $24 \mathrm{~h}$ ) was greater. We were also able to analyse the prevalence and incidence of diarrhoea and ALRI with different definitions. As discussed above, the frequent visits must have had some positive effect on the course of the episodes of diarrhoea and ALRI. Our results corroborate those of the Ghana trial, which showed a greater impact on the severity than on the occurrence of disease. ${ }^{6,12}$ Nevertheless, in our trial the overall incidence of diarrhoeal episodes was $6 \%$ lower in the vitamin-A-supplemented group.

With the standard definition of diarrhoea $(\geqslant 3$ liquid or semi-liquid stools in $24 \mathrm{~h}$ ), the difference in mean daily prevalence between the groups did not reach statistical significance. However, as the definition of diarrhoea was made more stringent, significant differences in favour of the supplemented group were seen. With the parent or guardian's definition of diarrhoea, the mean daily prevalence was $11 \%$ lower in the supplemented group $(p=0.012)$. Since the duration of the episodes, as well as the number of liquid or semi-liquid motions per $24 \mathrm{~h}$, can be taken as a proxy of diarrhoea severity, ${ }^{21}$ our results show a clear protective effect of vitamin A supplementation against severe diarrhoea. This effect was so strong that it was reflected in a decrease in the overall incidence of diarrhoea in the vitamin-A-supplemented group. There is strong evidence that the main effect of vitamin A supplementation on childhood mortality is on diarrhoea-related deaths. ${ }^{9}$ Since the more severe diarrhoea episodes carry a higher risk of mortality, ${ }^{23}$ the effect of vitamin A supplementation on diarrhoea severity may be the most important factor in the reduction in mortality with vitamin A supplementation. The low frequency of measles associated with diarrhoea episodes we found does not support the hypothesis ${ }^{24}$ that the effect on diarrhoea could be secondary to an effect of vitamin A supplementation on measles severity. ${ }^{9}$

We thank the regional office, Ministry of Health, particularly Mr Odilon Santos, for use of facilities; workers from Legiao Brasileira de Assistencia for introducing our team to the local community; project driver Mr Ademario Santos; nutritionists Ms Denise Amorim and Ms Maisa Cruz Martins, and UFBA nutrition students who collaborated in the field work; Dr Luciana Silva, Dr Clotilde Melo, and residents from the University Hospital and Department of Preventive Medicine for clinical examinations; Dr Jose Martines and Dr Roger Shrimpton fo encouragement and support; Ms Sharon Huttly and Mr Saul Morris for help with data analysis; Dr David Ross for useful comments on the paper; and especially the mothers, fathers, and guardians who gave permission for their children to take part in this study.
The study was supported by research grants from Diarrhoeal Disease Control Programme/WHO, UNICEF, and Instituto Nàcional de Alimentacàó e Nutricào/Minisfério dà Saúde, Brazil.

\section{References}

1 Sommer A, Tarwotjo J, Diunaedi E, et al. Impact of vitamin A supplementation on childhood mortality: a randomised controlled community trial. Lancet 1986; ii: 1169-73.

2 Muhilal, Permeisih D, Idjradinata YR, et al. Vitamin A fortified monosodium glutamate and health, growth and survival of children: a controlled field trial. Am $\mathcal{Y}$ Clin Nutr 1988; 48: 1271-76.

3 Rahmathullah L, Underwood BA, Thulasiraj RD, et al. Reduced mortality among children in Southern India receiving a small weekly dose of vitamin A. N Engl f Med 1990; 323: 929-35.

4 West KP, Pokherel RP, Katz S, et al. Efficacy of vitamin A in reducing child mortality in Nepal. Lancet 1991; 338: 67-71.

5 Daulaire NMP, Starbuck ES, Houston RM, et al. Childhood mortality after a high dose of vitamin A in a high risk population. BMF 1992; 304: 207-10.

6 Ghana VAST Study Team. Vitamin A supplementation in northern Ghana: effects on clinic attendances, hospital admissions, and child mortality. Lancet 1993; 342: 7-12.

7 Vijayaraghavan K, Radhaiah G, Prakasam BS, Sarma KVR, Reddy V. Effect of massive dose vitamin A on morbidity and mortality in Indian children. Lancet 1990; 336: 1342-45.

8 Herrera HG, Nestel P, El Amin A, et al. Vitamin A supplementation and child survival. Lancet $1992 ; 340: 267-71$

9 Beaton GH, Martorell R, L'Abbe KA, et al. Effectiveness of vitamin A supplementation in the control of young child morbidity and mortality in developing countries. Final report to CIDA. Toronto, University of Toronto; 1993.

10 Fawiz WW, Chalmers TC, Herrera MG, Mosteller F. Vitamin A supplementation and child mortality; a meta-analysis. F $A M A 1993$; 269: 898-903.

11 Glaziou PP, Mackerras DEM. Vitamin A supplementation and infectious diseases: a meta-analysis. BMF 1993; 306: 366-70.

12 Arthur P, Kirkwood B, Ross D, et al. Impact of vitamin A supplementation on childhood morbidity in northern Ghana. Lancet 1992; 339: 361-62.

13 Rahmathullah L, Underwood BA, Thulasiraj RD, Milton RC. Diarrhoea, respiratory infections and growth are not affected by a weekly low-dose vitamin A supplement: a masked, controlled field trial in children in southern India. Am F Clin Nutr 1991; 54: 568-77.

14 Dibley MJ, Sadjimin T, Kjolhede CL. Impact of high dose vitamin A supplementation on incidence and duration of episodes of diarrhoea and acute respiratory infections in preschool Indonesian children. FASEB F 1992; 6: Al787 (abstr 4923).

15 Stansfield SK, Pierre-Louis M, Lerebours G, Augustin A. Vitamin A supplementation and increased prevalence of childhood diarrhoea and acute respiratory infections. Lancet 1993; 341: 578-82.

16 Santos LMP, Dricot JM, Asciutti LS, Dricot d'Ans C. Xerophthalmia in the state of Paraiba, northeast Brazil: clinical findings. Am f Clin Nutr 1983; 38: 139-44.

17 Dricot d'Ans C, Dricot JM, Diniz AS, Mariath JGR, Santos LMP. Geographic distribution of xerophthalmia in the state of Paraiba, Northeast Brazil. Ecol Food Nutr 1988; 22: 131-38.

18 WHO. Control of vitamin A deficiency and xerophthalmia: report of a joint WHO/UNICEF/USAID/HKI/IVACG meeting. WHO Tech Rep Ser 1982: 672

19 Organización Mundial de la Sàlud. Medición del cambio del estado nutricional. OMS, Geneva; 1983.

20 Baqui AH, Black RE, Yunus MD, et al. Methodological issues in diarrhoeal diseases epidemiology: definition of diarrhoeal episodes. Int 7 Epidemiol 1991; 20: 1057-63.

21 Lulseged S. Predictors of moderate to severe dehydration in acute diarrhoeal disease: a case-control study. Ethiop Med f 1992; 30: 69-78.

22 Schorling JB, Wanke CA, Schorlin SK, et al. A prospective study of persistent diarrhoea among children in an urban Brazilian slum. Am F Epidemiol 1990; 132: 144-56.

23 Griffin PM, Ryan CA, Nyaphisi M, et al. Risk factors for fatal diarrhoea: a case control study of African children. Am $\mathcal{F}$ Epidemiol 1988; 128: 1322-29.

24 Latham M. Vitamin A and child mortality. Lancet 1993; 342: 549. 